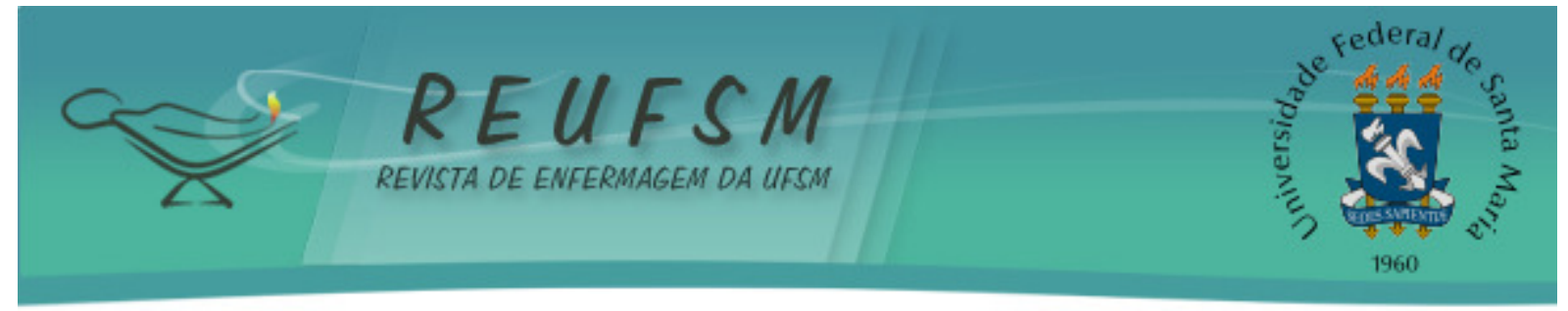

ARTIGO ORIGINAL

\title{
SER CUIDADORA FAMILIAR DE CRIANÇA COM ASMA: ANÁLISE DO DISCURSO E ESTUDO DE SUAS SIGNIFICAÇÕES ${ }^{1}$
}

\author{
BEING A CAREGIVER OF A CHILD WITH ASTHMA: DISCOURSE ANALYSIS AND STUDY OF \\ ITS MEANINGS
}

\section{SER CUIDADORA DE UNO NIÑO CON ASMA: ANÁLISIS DEL DISCURSO Y ESTUDIO DE SU SIGNIFICADOS}

\author{
Neila Santini de Souza ${ }^{2}$ \\ Eliane Tatsch Neves ${ }^{3}$ \\ Regina Issuzu Hirooka de Borba ${ }^{4}$
}

\section{Doi: $10.5902 / 2179769210991$}

RESUMO: Objetivo: identificar a formação discursiva e os sentidos de uma cuidadora familiar de criança com asma. Método: pesquisa descritiva, abordagem qualitativa, que utilizou o Método Criativo - Sensível com familiares de crianças com asma, aplicando a Dinâmica de Criatividade e Sensibilidade (DCS) Costurando Estórias. Os dados foram interpretados tendo por base teórica a Análise do Discurso de linha francesa. Resultados: evidenciou-se na formação discursiva de uma cuidadora que o sentido é determinado pela posição-sujeito em questão, desvelando o político, o ideológico e o social em funcionamento. Conclusões: é necessário rever as formas de discursividades, propondo uma atuação mais dinâmica como mediador do processo de cuidado compartilhado com a família.

DESCRITORES: Asma; Cuidadores; Linguística; Enfermagem familiar.

ABSTRACT: Aim: to know the discursive formation and meanings of being a family caregiver of a child with asthma. Method: a descriptive, qualitative approach, which used the creative method - Sensitive developed with families of children with asthma, where we used the Dynamic Creativity and Sensitivity (DCS) Sewing Stories. Data were submitted to discourse analysis in its French strand. Results: it is evident in the discursive formation of the caregiver that meaning is determined by ideological positions, revealing the political and ideological social functioning. Conclusions: it is necessary to review the forms of interaction with the family and act as mediator in shared care with families.

DESCRIPTORS: Asthma; Caregivers; Linguistics; Family nursing.

RESUMEN: Objetivo: identificar la formación discursiva y los significados de una cuidadora familiar de un niño con asma. Método: investigación descriptiva, abordaje cualitativo, que utilizó el Método Creativo - sensible con familiares niños con asma,

\footnotetext{
${ }^{1}$ Trabalho final de componente curricular optativo cursado durante o primeiro semestre de 2013, apresentado na Disciplina de Estudos da Significação do Curso de Doutorado do Programa de Pós-Graduação em Letras da Universidade Federal de Santa Maria/UFSM.

${ }^{2}$ Enfermeira. Doutoranda em Enfermagem do Doutorado Interinstitucional promovido pelo Programa de PósGraduação em Enfermagem da UNIFESP/UFRJ/UFSM - DINTER Novas Fronteiras, Professora Assistente do Curso de Graduação em Enfermagem da Universidade Federal do Pampa/UNIPAMPA - Campus Uruguaiana/RS, Brasil. E-mail: neilasantini25@gmail.com

${ }^{3}$ Enfermeira. Doutora em Enfermagem. Professora Adjunta do Departamento de Enfermagem e Professora Permanente do Programa de Pós-graduação em Enfermagem do Centro de Ciências da Saúde da Universidade Federal de Santa Maria/UFSM - RS, Brasil. E-mail: elianeves03@gmail.com

${ }^{4}$ Enfermeira. Doutora em Enfermagem. Professora Associada do Departamento de Enfermagem Pediátrica e Professora Permanente do Programa de Pós-graduação em Enfermagem da Escola Paulista de Enfermagem da Universidade Federal de São Paulo/UNIFESP - SP, Brasil. E-mail: rihborba@unifesp.br
} 


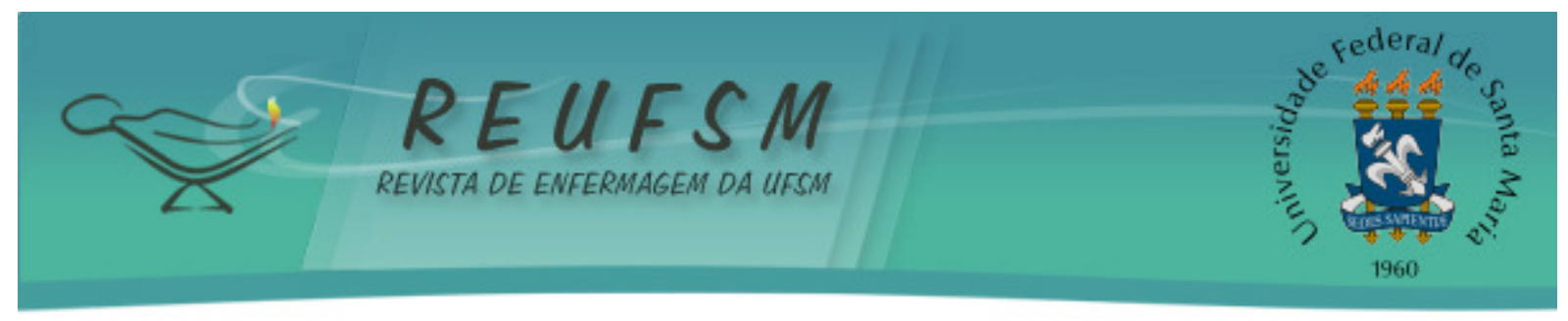

aplicando la Dinámica de Creatividad y Sensibilidad (DCS) Costurando Historias. Los datos fueron sometidos al análisis de discurso en la corriente francesa. Resultados: es evidente en la formación discursiva de la cuidadora de que el significado está determinado por la posición-sujeto en cuestión, revelando el funcionamiento político, ideológico y social. Conclusiones: es necesario revisar las formas de discursos, que propone un papel más dinámico como mediador del proceso de atención compartida con la familia.

DESCRIPTORES: Asma; Cuidadores; Lingüística; Enfermería de la familia.

\section{INTRODUÇÃO}

Ao reconhecer as dificuldades que os familiares das crianças com asma possuem para prover o cuidado no domicílio, o enfermeiro pode auxiliar na promoção da autonomia e do empoderamento da família para estes cuidados. A necessidade de assumir o cuidado no domicílio evidencia a importância do estudo da subjetividade nas relações interpessoais e a importância de refletir sobre a troca de saberes entre usuários dos serviços de saúde e os profissionais, sendo imprescindível respeitar as expectativas e os sentidos de cada cuidador familiar. ${ }^{1}$

A asma é uma doença inflamatória crônica de alta incidência em crianças e adolescentes no mundo, constitui importante problema de saúde pública no Brasil, sua prevalência vem aumentando nos últimos anos, possui relevante morbidade $\mathrm{e}$ consequências negativas para crianças e familiares. ${ }^{2}$ Estudo sobre a asma infantil e o mundo familiar e social da criança, enfatizou a importância de que a asma exige um tratamento interdisciplinar, que contemple as dimensões biológica, psicológica e social na visão de uma assistência engajada que considere o paciente e sua família em seu mundo sociocultural. Além disso, constatou-se que sessões de brinquedo terapêutico foram benéficas às crianças, pois auxiliaram inclusive no seu quadro clínico, sendo que, para a família, proporcionou a possibilidade de conhecer melhor a criança e suas potencialidades. $^{3}$

Como doença crônica não transmissível, a asma em crianças tornou-se foco de ações estratégicas do Ministério da Saúde no Brasil desde o ano de 2011. ${ }^{4}$ No Brasil pouco tem sido investigado a respeito do comportamento da asma segundo as diferentes regiões do país. Compreender melhor a dinâmica desse complexo processo de cuidar de crianças com asma pode contribuir para a implementação de políticas públicas dirigidas à promoção de saúde e equidade. ${ }^{5}$ Os benefícios para a saúde, a partir de programas de controle da asma estão conduzindo a uma marcante redução dos índices de mortalidade e das hospitalizações, nos países desenvolvidos e em desenvolvimento, porém sem influência na sua morbidade. Em um estudo envolvendo 3748 crianças de nível socioeconômico baixo, nos Estados Unidos, um programa educativo teve como resultado uma diminuição de $35 \%$ nos índices globais de hospitalização, uma diminuição de $27 \%$ no recurso a serviços de urgência devido à asma e uma diminuição de $19 \%$ das consultas externas. 0 número de pessoas com asma aumentou, apesar de a morbimortalidade terem diminuído significativamente. ${ }^{6}$

Ao entender melhor a situação real dos cuidados no domicílio desenvolvidos pelos familiares cuidadores, por meio de uma interpretação discursiva, tendo por foco o entendimento dos sentidos de um cuidador familiar de criança com asma, é possível compreender melhor suas expectativas, medos, receios e dificuldades no cuidado da criança. Dessa forma, pode o profissional de saúde, e, especialmente, o enfermeiro, realizar um planejamento adequado na atenção à saúde, a partir das demandas do familiar e da criança, construindo de forma compartilhada um plano de cuidados para uma vivência cotidiana de menor sofrimento e sobrecarga tanto para o mesmo quanto para a criança. ${ }^{7}$ 


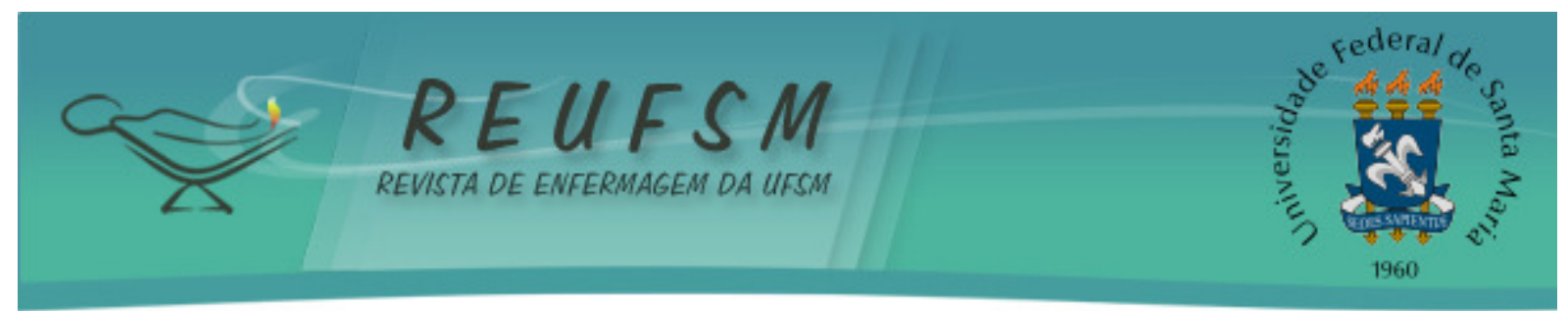

Os profissionais de saúde precisam compreender o cuidado familiar, observando todos os aspectos que envolvem este processo, particularmente em cada família, com o intuito de amenizar as fragilidades identificadas. ${ }^{8}$ Como questão norteadora deste estudo tem-se: Como uma cuidadora familiar de criança com asma socializa por meio de seu discurso as experiências e sentidos em cuidar em um encontro dialógico grupal entre familiares e a enfermeira-pesquisadora? Portanto, o objetivo é analisar a formação discursiva e os sentidos de ser uma cuidadora familiar de criança com asma.

\section{MÉTODO}

Pesquisa descritiva, com abordagem qualitativa que utilizou o Método Criativo Sensível $^{9}$ e foi desenvolvida com doze familiares cuidadoras de crianças com asma. A pesquisa obteve aprovação pelo Comitê de Ética em Pesquisa com Seres Humanos do Hospital São Paulo da Universidade Federal de São Paulo com o certificado de apresentação para apreciação ética (CAAE) número 07634512.4.0000.5505 em 05/10/2012, sendo conduzida de acordo com os padrões éticos exigidos. 0 cenário do estudo foi 0 Programa Infantil de Prevenção da Asma (PIPA), que funciona em uma policlínica infantil da secretaria municipal de saúde no município de Uruguaiana/RS.

Os dados foram produzidos, transcritos e analisados a partir da Dinâmica de Criatividade e Sensibilidade (DCS) que constituiu o eixo estruturante do Método Criativo Sensível, durante o período de novembro de 2012. Critérios de inclusão: ser familiar cuidador de criança com asma, que estivessem presentes em consultas de acompanhamento ou de retorno, nos últimos três meses. Critério de exclusão: ser cuidador de criança maior de cinco anos.

As DCS conjugam técnicas consolidadas de coleta de dados da pesquisa qualitativa, tais como, a entrevista coletiva, a discussão grupal e a observação participante para produzir dados no espaço do grupo de forma dinâmica, dialógica e interacional. ${ }^{10} \mathrm{~A}$ dinâmica desenvolve os procedimentos da pesquisa qualitativa, oportunizando o exercício do senso crítico e reflexivo e apresenta, no processo de criação artística, a sensibilidade mediada pela escuta sensível como força produtora de dados para a pesquisa.

0 referencial teórico utilizado nesta pesquisa tem como base a Teoria Libertadora de Paulo Freire na perspectiva do empoderamento dos sujeitos para cuidar de uma criança com asma. O corpus utilizado para essa análise foi constituído durante um encontro grupal para a produção dos dados desta pesquisa, onde uma das Dinâmicas de Criatividade e Sensibilidade (DCS) ${ }^{10}$ utilizadas na pesquisa, denominada Costurando Estórias, foi desenvolvida com três cuidadoras familiares de crianças com asma.

Entretanto, neste artigo, para a análise discursiva foi selecionado o discurso de uma cuidadora familiar, co-partícipe do estudo, em que foi feita uma análise do seu discurso e dos sentidos por ela produzidos partindo-se do referencial de que é pela linguagem que pode-se entender o outro e nós mesmos.

Para preservar a identidade da participante, a mesma foi denominada neste trabalho como Leoniza, sendo ela a avó da criança P.V. de dois anos de idade, que nasceu de parto vaginal e foi criada pela própria mãe até o seu primeiro ano de vida. A partir desta idade, passou a ser cuidada pela avó Leoniza, pois a mãe não tinha condições sociais de fazê-lo por ser prostituta e usuária de drogas.

Desde junho de 2012 a criança começou a apresentar "problema de peito" do tipo bronquite alérgica e muita secreção pulmonar segundo a avó. P.V. não chegou a ser internada nenhuma vez para tratamento de saúde, mas utiliza um tipo de medicação no domicílio diariamente, bem como faz uso de "bombinha" (medicação) quando ocorrem as crises de asma. 


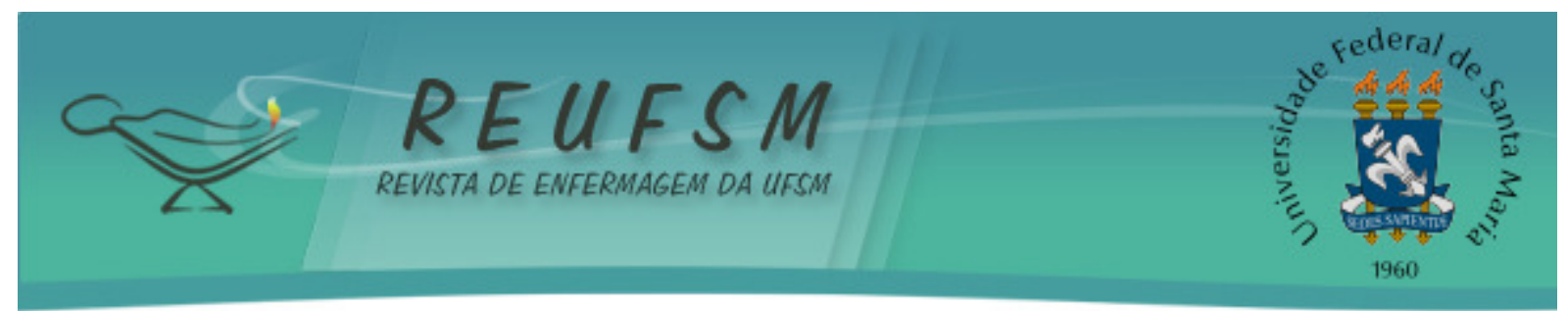

Leoniza possui 60 anos, três filhos, sendo que é a principal cuidadora de P.V.; seu marido trabalha o dia todo e ela se dedica exclusivamente aos cuidados do lar e da neta, que é a segunda a ser criada por ela. Considerando as posições discursivas do sujeito cuidador no encontro dialógico mediado pela linguagem, a análise do material empírico foi orientada pelos referenciais da Análise de Discurso em sua corrente francesa (AD). ${ }^{11}$

\section{RESULTADOS E DISCUSSÃO}

No campo teórico discursivo, para todo analista do discurso, são materiais de reflexão os escritos, as imagens de toda ordem, os ditos, as novas tecnologias, inclusive o silêncio, dentre muitos outro. Cada qual com suas especificidades. 0 dispositivo analítico bem como sua contribuição para a compreensão dos processos de significação, acontecem pelo trabalho com a abertura pelo simbólico. ${ }^{12}$ Portanto, diante do discurso da cuidadora familiar, é preciso que o pesquisador esteja atento ao simbólico mencionado em sua discursividade, como é o caso desta situação no recorte a seguir:

Eu acho assim ó, eu não sei, eu não me sinto preparada, entende? [...] mas eu não estou preparada para a hora que ela tem aquelas crises. Eu me ataco, eu choro, eu fico caminhando para um lado, para o outro e rezo, e peço para Deus que tire aquilo dela e (...) eu acho que eu passo meu nervosismo para ela. (Leoniza, primeiro recorte)

O simbólico mencionado no discurso da cuidadora, pelo que Deus representa em sua vivência e o significado do sofrimento em seu cotidiano, podem ser destacados de seu discurso e serem objetos para a intervenção do profissional de saúde/pesquisador que está atento às demandas das necessidades individuais da familiar cuidadora.

Cabe salientar também, que em seu discurso a cuidadora não menciona palavras que estejam associadas à doença da neta em muitas ocasiões, referindo-se a "aquilo" em seu discurso, pois a mesma possui um efeito simbólico que lhe causa sofrimento.

O que o homem fala é um enigma, algo misterioso, podendo ser objeto de dúvida, por exemplo, afinal com línguas sociais tão diferentes e algumas vezes incompreensíveis, à primeira vista pode ser inexplicável. ${ }^{13}$ Ouvir falar não pode antes de qualquer coisa ser surdo à diversidade dos ruídos. Falar é comunicar, comunicar-se, sendo que o simbólico está em funcionamento o tempo todo, e a língua é, antes de tudo, o lugar da intersubjetividade, é o lugar onde os indivíduos se confrontam, onde existe o encontro com o outro. ${ }^{14}$

Quando a cuidadora utiliza a paráfrase, referindo-se aos cuidados que o seu marido possui com os horários das medicações da neta, fica evidente o lugar da intersubjetividade na relação com o outro, pois a partir de sua linguagem é possível também identificar dispositivos analíticos do discurso utilizados durante sua comunicação:

O meu marido, é cinco horas "cravado", tá dando o remédio pra guria. Se tiver que ir às quatro horas dar o remédio para ela, lá na creche, ele pega a bicicleta dele e vai lá. Pode tá o sol ou o "tororó" que tiver, ele vai lá dar o remédio pra ela. É "caxias" no horário do remédio dela. (Leoniza, segundo recorte)

Algumas das palavras utilizadas pela cuidadora, como "cravado", "tororó" e "caxias" reporta ao dispositivo analítico denominado como metáfora, pois utiliza a linguagem simbólica para referir-se respectivamente "ao horário certo de ser dada a 


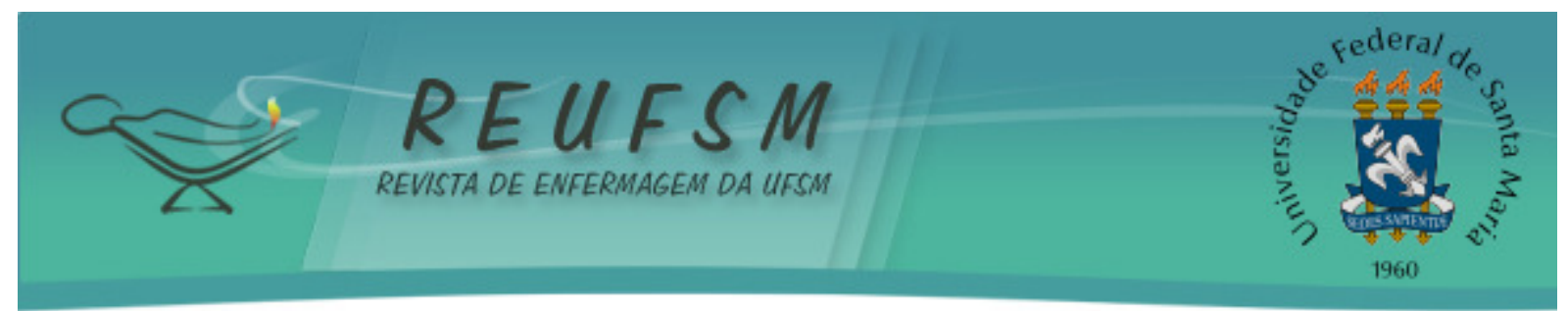

medicação", "ao tempo quando está para chuva" e "ao marido ser muito certinho com relação aos horários de administrar a medicação para a neta".

A intersubjetividade é atravessada pelo social-histórico em funcionamento de cada sujeito e a história no discurso é o lugar da significação. Aquilo que uma expressão significa é o que ela pode trazer para uma sentença, o sentido é visto como o que tal expressão traz para as condições de verdade de uma sentença, ou seja, é algo que diz respeito à relação desta sentença com fatos no mundo. E no estudo da significação, para o discursivo, faz-se necessário reconhecer as unidades mínimas de significação, já para o semântico trata-se de compreendê-la, por meio do discurso. ${ }^{15}$

Incluir o silêncio, a partir da análise das discursividades, é incluir o absolutamente excluído pelo corte saussureano, o silêncio é constitutivo da linguagem, pois considera-se que a linguagem não é transparente, consequentemente o discurso é o lugar em que se pode observar a relação entre língua e ideologia, compreendendo-se como a língua produz sentidos por/para os sujeitos. ${ }^{15}$

Portanto, não existe discurso inocente e neutro, todos reproduzem uma forma de ideologia, diante disso. Pode-se, inclusive, afirmar ainda, que é o ponto de vista, ou seja, a direção que cria o objeto e a realidade. Ele passa a ter valor quando contextualizado ao cotidiano dos sujeitos. Para Leoniza, a cuidadora familiar, o discurso como acontecimento se dá no momento de falar sobre sua situação existencial e seu cotidiano de cuidados com a neta, que convive com a asma.

Leoniza, fala a partir de seu lugar social de avó cuidadora, revelando a sua formação discursiva no momento das enunciações, direcionadas para uma profissional de saúde, enfermeira e pesquisadora. Do seu lugar social, enquanto mulher cuidadora, mostra as marcas discursivas do desespero e sobrecarga, por sentir-se sozinha para cuidar da neta, o que fica evidente principalmente nos momentos das crises de asma. A cuidadora mostra esse fato e o traz como exemplo a partir do seguinte recorte:

Quando ela chegou, para mim, ela chegou assim ó [...] no último! Que a gente pegou ela, [...] ela estava com, muito atacada do peito, estava até com ameaça de pontada (pneumonia) Então, a gente se apavorou, porque a gente nunca teve um filho assim. Tive seis filhos [...] uma neta até os quinze anos [...] e nunca tinha acontecido isso aí pra mim. Que até agora qualquer coisinha que dá eu saio desesperada com ela. (Leoniza, terceiro recorte)

$\mathrm{Na}$ formação discursiva, em questão, o sentido não existe em si, mas é determinado pelas posições ideológicas colocadas em jogo no processo sócio-histórico em que as palavras são produzidas, determinando o que pode e deve ser dito, pois os sentidos sempre são determinados ideologicamente. ${ }^{16}$

Leoniza utiliza em alguns momentos a linguagem aprendida na sua relação com os demais profissionais da saúde, dando ênfase aos termos relacionados ao vocabulário médico, como é o caso, por exemplo, das palavras anemia, asma, nebulização.

[...] Aí eu faço uma nebulização né, porque ela acalma. Mas imagina assim, ó, cada vez que dá essas crises nela, eu vou tacar bombinha nela, aí ela vai se acostumar, né? (Leoniza, quarto recorte)

Seu discurso valoriza a figura do profissional médico no tratamento da criança, o que mostra o político, o ideológico e o social em funcionamento. Na atenção à saúde médico-centrada, a avó acaba parafraseando a linguagem do discurso médico, quando se 


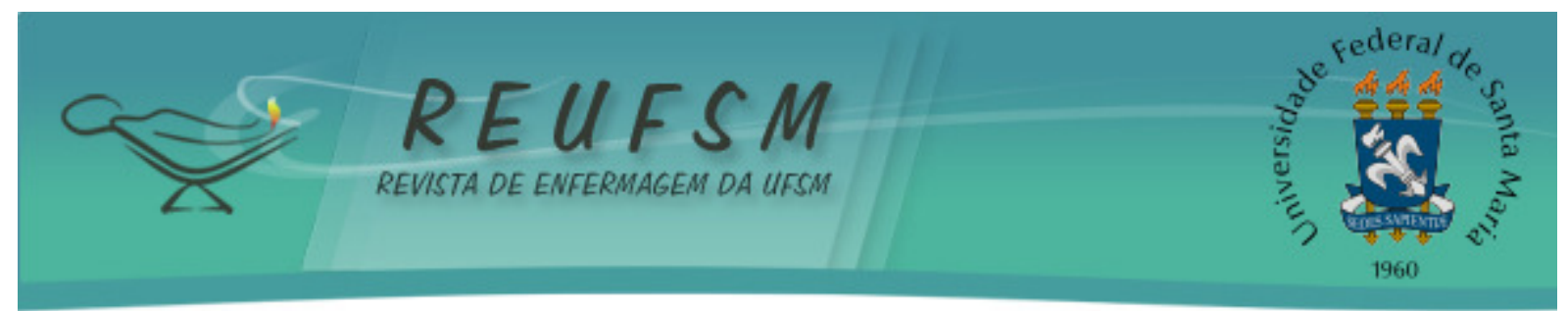

refere aos cuidados com a neta e sua experiência como avó cuidadora. Portanto, os processos parafrásticos no discurso da avó são aqueles pelos quais em todo dizer há sempre algo que se mantém, ou seja, o dizível, a memória discursiva. A paráfrase representa assim o retorno aos mesmos espaços do dizer, produzindo diferentes formulações do mesmo dizer sedimentado. ${ }^{15}$

A fala de Leoniza é alternada por momentos de paráfrase e outros de polissemia, enquanto a paráfrase está do lado da estabilização do sentido, na polissemia tem-se o deslocamento dele, derivando para outro lugar, causando uma ruptura dos processos de significação. Estas duas forças trabalham continuamente o dizer, pois se sabe que todo discurso se faz na tensão entre o mesmo e o diferente. ${ }^{15}$

[...] pra mim está sendo difícil criar ela por causa disso aí. Porque [...] quando dá uma crise nela, [...], eu fiquei assim desesperada. [...] Então eu penso assim ó, eu digo meu Deus, o que eu vou fazer com essa inocente? (Leoniza, quinto recorte)

Polissemicamente, a familiar cuidadora significou em seus discurso a sobrecarga de ser cuidadora de uma criança que apresenta crises de asma, o que é enfatizado pelo desespero e nervosismo. A polissemia marca o discurso da cuidadora, enfatizando aquilo que é diferente em seu cotidiano de cuidados com a neta.

A substituição do termo "disso aí” no dizer da avó, neste movimento analítico, por "doença/asma", dá visibilidade aos sentidos que emergem do não-dito na fala dela, sendo este um trabalho de memória e esquecimento de dizeres que produzem sentidos e que são apagados no momento que ela enuncia. A substituição da palavra asma produz novos sentidos no jogo discursivo do cotidiano que é constituído de uma variedade de cuidados para garantir a saúde da neta que possui uma doença crônica.

Isto traz a tona os sentidos que circulam socialmente no imaginário coletivo do que é estar e conviver com a asma, estabelecendo relações que qualificam negativamente o sujeito que possui a doença. ${ }^{16} \mathrm{O}$ silenciamento ou a ausência de palavras apontam um modo de apagar sentidos onde "o silêncio fala por elas". ${ }^{15}$

\section{CONCLUSÃO}

Espera-se que o estudo contribua para $o$ ato de cuidar em enfermagem na perspectiva da inclusão da família nos cuidados, bem como, para a elaboração de políticas públicas que propiciem o acesso aos serviços de saúde às crianças com asma e seus familiares. Entre as limitações desta pesquisa, destaca-se a participação de uma familiar cuidadora na DCS costurando estórias, porém, para a análise deste corpus, pôde-se obter material significativo para atingir o objetivo proposto deste artigo.

Sugere-se que outras pesquisas possam ser realizadas, utilizando novas abordagens metodológicas e de intervenção, para que se possa, cada vez mais, incluir a família no cuidado compartilhado, em que a criança também seja ativa no processo de auto-cuidar-se e auto-gerir seu tratamento e terapêutica, assim que sua compreensão permitir. Os dados implicam também em novas pesquisas direcionadas às crianças, enquanto participantes em novos desenhos de pesquisa.

Alguns aspectos são fundamentais no trabalho com familiares cuidadores. Destacase que a aproximação do enfermeiro e dos demais profissionais de saúde com a família no processo terapêutico é favorecida quando é assumida uma postura flexível, de escuta do outro, utilizando uma posição em uma alteridade sem limite, onde a troca de saberes 


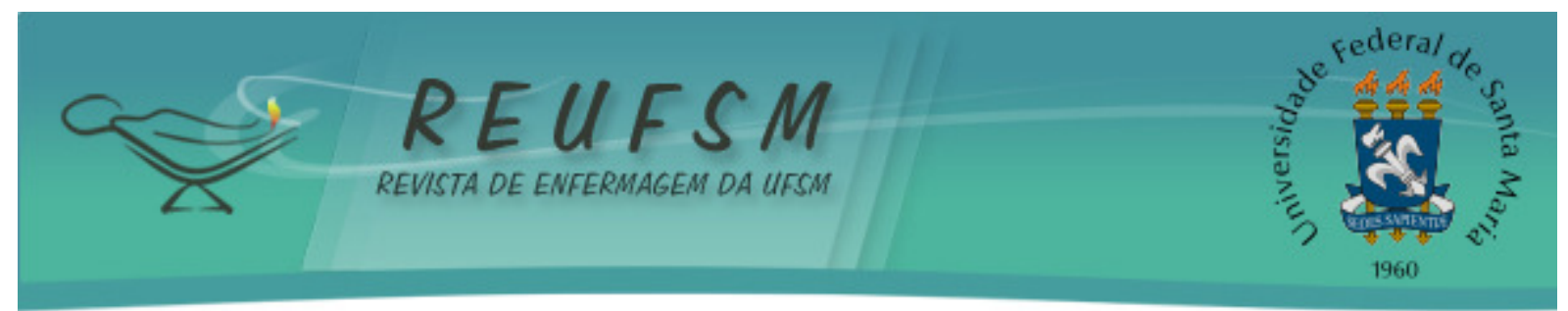

ocorre de forma não horizontal, mas dialógica, em que se considere a demanda do familiar e de sua realidade.

A Análise do Discurso, enquanto disciplina e metodologia, auxilia na compreensão da família/ da familiar cuidadora e suas atitudes frente à aparente negligência na terapêutica de cuidado.

Este processo pode ser determinado por questões externas à família, pelo impacto dos sentidos a que eles são submetidos pelos próprios profissionais de saúde e da linguagem utilizada nos processos educativos, onde ainda predomina um único detentor do saber (o profissional), bem como é determinado pelo social em funcionamento, e da mesma forma, como os integrantes são assujeitados ideologicamente pelo social imposto pela história da doença.

Diante destes aspectos, a família não pode ser culpabilizada pela frustração no processo terapêutico, pois enquanto profissional de saúde, faz-se necessário rever as formas de discursividades com o familiar, propondo uma atuação mais dinâmica para poder atuar ativamente como facilitador no processo educativo e como mediador do processo de cuidado compartilhado com a família.

\section{REFERÊNCIAS:}

1. Paiva RS, Valadares GV, Silva JS. The need to become family caregivers: qualitative study focusing on the theory based on data. Online Braz J Nurs [Internet]. 2012 dez [acesso em 2013 jul 22];11(3):607-20. Disponível em: http://www.objnursing.uff.br/index.php/nursing/article/view/3638.

2. Wehrmeister FC, Menezes AMB, Cascaes AM, Martínez-Mesa J, Barros AJD. Tendência temporal de asma em crianças e adolescentes no Brasil no período de 1998 a 2008. Rev Saúde Pública [Internet]. 2012 abr [acesso em 2013 jul 20];46(2):242-50. Disponível em: http://www.scielo.br/pdf/rsp/v46n2/3371.pdf.

3. Borba RIH, Sarti CA. A asma infantil e o mundo social e familiar da criança. Rev Bras Alergia Imunopatol [Internet]. 2005 [acesso em 2013 jul 22];28(5):249-54. Disponível em: http://www.asbai.org.br/revistas/Vol285/asma_intantil.pdf.

4. Brasil. Ministério da Saúde. Brasil Carinhoso I. Farmácia Popular terá remédio de graça para asma [Internet]. Brasília (DF); 2012 [acesso em 2013 jul 13]. Disponível em: http://portalsaude.saude.gov.br/portalsaude/noticia/5034/162/farmacia-popular-tera-

\%3Cbr\%3Eremedio-de-graca-para-asma.html.

5. Wehrmeister FC, Peres KGA. Desigualdades regionais na prevalência de diagnóstico de asma em crianças: uma análise da Pesquisa Nacional por Amostra de Domicílios, 2003. Rev Saúde Pública [Internet]. 2010 set [acesso 2013 jul 20];26(9):1839-52. Disponível em: http: //www.scielo.br/pdf/csp/v26n9/17.pdf.

6. Bousquet J, Khaltaev N, editores. Organização Mundial da Saúde. Vigilância global, prevenção e controlo das doenças respiratórias crónicas: uma abordagem integradora [Internet]. Lisboa; 2008 [acesso em 22 jul 13]. Disponível em: http://www.who.int/gard/publications/GARD_Portuguese.pdf.

7. Souza NS, Neves ET, Borba RIH. Family care for children with asthma: a descriptive study. Online braz j nurs [Internet]. 2013 Oct [2013 out 10]; 12 Suppl: 659-61. Disponível em http://www.objnursing.uff.br/index.php/nursing/article/view/416. 


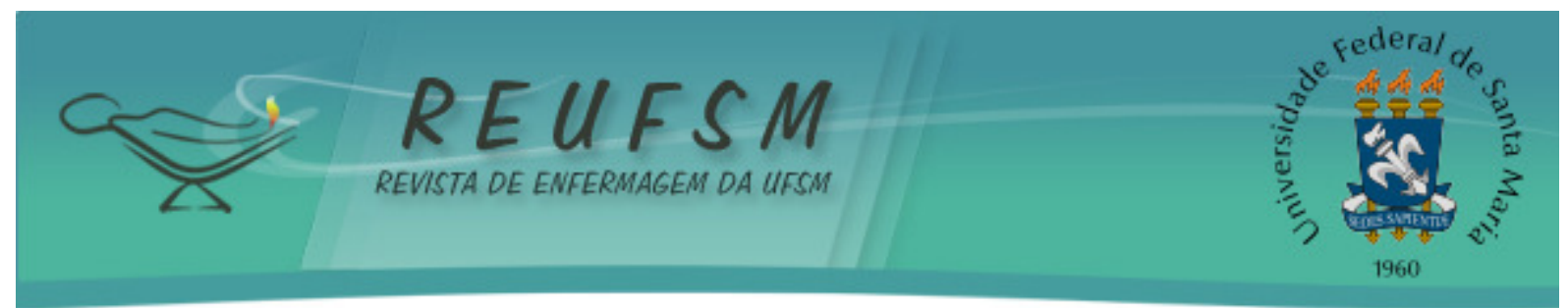

8. Silveira CL, Budó MLD, Silva FM, Durgante VL, Wünsch S, Simon BS, et al. Cuidadora de familiar com doença crônica incapacitante: percepções, motivações e repercussões. Rev Enferm UFSM [Internet]. 2012 jan/abr [acesso em 2013 jul 22];2(1):67-78. Disponível em: http://cascavel.ufsm.br/revistas/ojs-2.2.2/index.php/reufsm/article/download/3828/3128.

9. Neves ET, Cabral IE, Silveira A. Family network of children with special health needs: implications for Nursing. Rev Latinoam Enferm [Internet]. 2013 mar [acesso de 2013 jun 12];21(2):562-70. Disponível em: http://www.scielo.br/pdf/rlae/v21n2/0104-1169-rlae-2102-0562.pdf.

10. Cabral IE. O método criativo e sensível: alternativa de pesquisa na enfermagem. In: Gauthier JHM, Cabral IE, Santos I, Tavares CMM. Pesquisa em enfermagem: novas metodologias aplicadas. Rio de Janeiro: Guanabara Koogan; 1998. p.176-203.

11. Orlandi EP. Análise de discurso: princípios \& procedimentos. $9^{a}$ ed. São Paulo (SP): Pontes; 2010.

12. Pêcheux M. Análise de discurso: textos escolhidos por Eni Puccinelli Orlandi. $2^{\mathrm{a}}$ ed. Campinas (SP): Pontes; 2011.

13. Auroux S. A filosofia da linguagem. Campinas (SP): Unicamp; 1998.

14. Vogt C. $O$ intervalo semântico: contribuição para uma teoria semântica argumentativa. $2^{\mathrm{a}}$ ed. rev. Campinas (SP): Ateliê Editorial, Unicamp; 2009.

15. Guimarães E. Os limites do sentido: um estudo histórico e enunciativo da linguagem. Campinas (SP): Pontes; 1995.

16. Kessler TM. A surdez que se faz ouvir: sujeito, língua e sentido [tese]. Santa Maria (RS): Universidade Federal de Santa Maria; 2008. 236 p.

Data de recebimento: $15 / 10 / 2013$

Data de aceite: $27 / 11 / 2013$

Contato com autor responsável: Neila Santini de Souza

Endereço postal: BR 472, Km 592, Caixa Postal 118 - Universidade Federal do

Pampa/Campus Uruguaiana, RS. CEP: 97500-970.

E-mail: neilasantini25@gmail.com 